\title{
Airborne transmission of lyssaviruses
}

Correspondence

A. R. Fooks

t.fooks@vla.defra.gsi.gov.uk

Received 13 October 2005

Accepted 29 January 2006

\author{
N. Johnson, ${ }^{1}$ R. Phillpotts ${ }^{2}$ and A. R. Fooks ${ }^{1}$
}

${ }^{1}$ Rabies and Wildlife Zoonoses Group, Veterinary Laboratories Agency (VLA, Weybridge), WHO Collaborating Centre for the Characterisation of Rabies and Rabies-related Viruses, New Haw, Addlestone KT15 3NB, UK

${ }^{2}$ Defence, Science and Technology Laboratory (DSTL), Porton Down, Salisbury, UK
In 2002, a Scottish bat conservationist developed a rabies-like disease and subsequently died. This was caused by infection with European bat lyssavirus 2 (EBLV-2), a virus closely related to Rabies virus (RABV). The source of this infection and the means of transmission have not yet been confirmed. In this study, the hypothesis that lyssaviruses, particularly RABV and the bat variant EBLV-2, might be transmitted via the airborne route was tested. Mice were challenged via direct introduction of lyssavirus into the nasal passages. Two hours after intranasal challenge with a mouse-adapted strain of RABV (Challenge Virus Standard), viral RNA was detectable in the tongue, lungs and stomach. All of the mice challenged by direct intranasal inoculation developed disease signs by 7 days post-infection. Two out of five mice challenged by direct intranasal inoculation of EBLV-2 developed disease between 16 and 19 days post-infection. In addition, a simple apparatus was evaluated in which mice could be exposed experimentally to infectious doses of lyssavirus from an aerosol. Using this approach, mice challenged with RABV, but not those challenged with EBLV-2, were highly susceptible to infection by inhalation. These data support the hypothesis that lyssaviruses, and RABV in particular, can be spread by airborne transmission in a dose-dependent manner. This could present a particular hazard to personnel exposed to aerosols of infectious RABV following accidental release in a laboratory environment.

\section{INTRODUCTION}

The genus Lyssavirus within the family Rhabdoviridae comprises classical Rabies virus (RABV; genotype 1) and at least six additional genetically divergent lineages that discriminate the genotypes of virus within the genus. The viral genome is composed of a single, negative strand of RNA encoding five proteins: the nucleoprotein, phosphoprotein, matrix protein, glycoprotein and an RNA polymerase (Tordo, 1996). The genus Lyssavirus includes: Lagos bat virus (genotype 2), Mokola virus (genotype 3), Duvenhage virus (genotype 4), European bat lyssavirus 1 and 2 (EBLV-1 and -2, genotypes 5 and 6, respectively) and Australian bat lyssavirus (genotype 7) (Bourhy et al., 1993). Members of this genus can be placed into two broad groups. Genotypes 1, 4, 5, 6 and 7 belong to phylogroup I, whilst genotypes 2 and 3 have been placed in phylogroup II on the basis of glycoprotein sequence, pathogenicity and immunogenicity (Badrane et al., 2001). Additionally, there are at least four unclassified lyssaviruses - Aravan, Khujand, Irkut and West Caucasian bat virus - that have been isolated recently from bats in Eurasia and proposed as new members of the genus Lyssavirus, indicating that these are emerging zoonotic viruses (Botvinkin et al., 1996, 2003; Arai et al., 2003).

Abbreviations: CVS; Challenge Virus Standard; FAT, fluorescent antibody test.
Lyssaviruses are all capable of causing clinical 'rabies' disease in mammals. All genotypes, with the exception of Lagos bat virus, have been responsible for human fatalities (Fooks, 2004).

Lyssaviruses in bats present a public health risk and are classified as 'category $\mathrm{C}$ emerging infectious disease threats'. In Europe, classical rabies is being eliminated from much of the continent; however, two related viruses, EBLV-1 and -2, are widely distributed (Bourhy et al., 1992). Between 1985 and 2002, 673 cases of EBLV infection were detected; the majority ( $>95 \%$ ) of virus isolates were EBLV-1 and were predominantly associated with the Serotine bat (Eptesicus serotinus), whereas EBLV-2 appeared to be associated with Myotis species (Fooks et al., 2003a). In the UK, a recent fatality due to infection with EBLV-2 occurred in Scotland (Fooks et al., 2003b). A bat conservationist was diagnosed with rabies infection following exposure to bats; the route of transmission has never been accurately ascertained, although he admitted to numerous exposures involving close handling of different bat species and previously had been bitten by bats on some occasions whilst not wearing gloves. This is the first recorded case of indigenous human rabies in the UK in 100 years. In the majority of cases, animal-to-animal transmission of RABV occurs following saliva exposure after a bite from an infected animal (Warrell \& Warrell, 2004). In the Americas, however, 'cryptic 
transmission' of RABV bat variants to man is reported annually (Messenger et al., 2002). The 'small vector hypothesis' (Messenger et al., 2003) suggests a failure to recognize the seriousness of a bat bite, especially from a small bat, which accounts for numerous cryptic cases of human rabies as a result of being bitten. The bite is often unrecognized, largely due to the perceived negligible size of the lesion. As frequent urination and defecation is commonplace among bats, and a large amount of guano is present, resulting in the possibility of aerosolized virus, it is possible that vertical transmission of virus among bats in enclosed areas (caves, roof spaces and cellars) occurs as a result of airborne virus (Constantine, 1962, 1967; Winkler, 1968). Bats naturally infected with RABV have been shown to harbour virus in the nasal mucosa, leading to the supposition that airborne transmission of RABV between bats living in enclosed areas is possible (Constantine et al., 1972). The mechanism of virus transmission via the airborne route and the viral load required for dispersal are not known (Winkler, 1975). It is assumed that environmental conditions for airborne transmission (Winkler et al., 1972) and the virus titre will dictate the effectiveness of transmission. The possibility exists for exposure via the respiratory tract in susceptible hosts that enter an infected area (Atanasiu, 1965). As a consequence of exposure via the airborne route, it is suggested that this route provides an enhanced capability for RABV to invade the brain via the olfactory neuroepithelium and olfactory nerve in susceptible individuals (Jenson et al., 1969; Lafay et al., 1991). Human cases of rabies from accidental airborne transmission have been reported previously (Irons et al., 1957; Kent \& Finegold, 1960; Winkler et al., 1973; Tillotson et al., 1977; summarized in Table 1). It is possible that EBLV-2 can be transmitted by a number of routes, principally through bites, but also by the generation of local aerosols. To assess this, we compared EBLV-2 transmission via the airborne route with classical RABV.

\section{METHODS}

Viruses. The Challenge Virus Standard (CVS) strain of RABV was used as a representative of genotype 1. EBLV-2 strain RV1332 was isolated from a Daubenton's bat (Myotis daubentonii) in 2002 (Johnson et al., 2003). Both viruses were grown in BHK-21 cells ( $<10$ passages) using Leibovitz L-15 media (Invitrogen) with $1 \%$ fetal calf serum (FCS). At this concentration of FCS, both viruses grew suboptimally and, as a result, virus suspensions were prepared by combining the supernatant and trypsinized cell monolayer in an attempt to maximize the level of virus. TCID $_{50}$ (fluorescent foci of infected cells) was calculated using a tenfold serial dilution of BHK-21 cells as described previously (King, 1996). Suspensions were stored at $-70{ }^{\circ} \mathrm{C}$ until required.

Mouse strain. Male RIII mice (k/k haplotype) were used throughout the study (VLA stock, inbred, albino). Mice were provided with food and water ad libitum and all experiments were conducted under Home Office Project Licence 70/5327. Mice challenged with lyssavirus were monitored using a scoring system. This rated the mice as 0 (no effects), 1 (ruffled fur, hunched back), 2 (slow or circular movements, gait affected), 3 (trembling, shaking and lameness) and 4 (paralysis). Animals found with scores of 3 or above were killed humanely.

Virus challenge. Groups of mice $(n=5-7)$ were challenged by direct intracranial (i.c.) inoculation, intranasal (i.n.) inoculation or subdermally through the footpad. Aerosol exposure of groups of mice $(n=10)$ was achieved using a bespoke portable apparatus as described previously (Phillpotts et al., 1997). Briefly, compressed air (BOC) was used to create an aerosol from a Collison spray. Groups were exposed to the aerosol, unrestrained, in an $80 \mathrm{l}$ box, closed at one end, with a HEPA filter. Subsequently, the exposure cabinet was flushed out with air $\left(301 \mathrm{~min}^{-1}\right)$ for $10 \mathrm{~min}$ before the animals

Table 1. Reported cases of airborne transmission of rabies

\begin{tabular}{|ll|}
\hline Year & Comments \\
\hline $1956 \quad$ Rabies was confirmed in an entomologist who had worked in a number of caves in Texas \\
containing large colonies of Mexican Free-tailed bats. The patient had no recollection of \\
being bitten. \\
A consultant mining engineer was admitted to hospital in Los Angeles, California, on 1 June, \\
complaining of shortness of breath and retching. Rabies was confirmed following death. \\
Previously, he had been working in caves in both Mexico and Texas. No evidence of a \\
biting incident could be confirmed, although there was a report that he emerged from one \\
cave with a bleeding wound on his face. \\
A 56 -year-old veterinarian who had been working in a laboratory preparing rabies vaccine \\
developed headaches, vomiting, diarrhoea and general weakness. The patient had been \\
involved in the preparation of rabies vaccine from brain obtained from rabies-infected goats. \\
This process involved the use of a kitchen blender, which, on subsequent investigation, was \\
observed to produce a visible aerosol. \\
A further case of laboratory-acquired rabies was reported in 1977 in a 32-year-old technician, \\
who had been participating in experiments to prepare an oral vaccine by coating small pellets \\
with aerosolized virus. He felt weak and developed a fever. On admission to hospital, he \\
became lethargic and entered a comatose state. Unlike previous cases, the patient began to \\
recover from 3 May, although with neurological impairment.
\end{tabular}


were removed. All exposures were undertaken within a microbiological safety cabinet operating at class III mode under guidelines covering Advisory Committee on Dangerous Pathogens Category 3/Specified Animal Pathogens Order Category 4 containment. Immediately following exposure, two mice from the control group exposed to medium and the highest virus titre group were sacrificed, and brain, tongue, lungs and stomach were removed and stored at $-70{ }^{\circ} \mathrm{C}$. The remaining mice were transferred to a flexible-film isolator (Bell Isolation Systems) and monitored twice daily for 28 days unless otherwise stated.

Following challenge, subjects were killed humanely when clinical signs of disease developed or at the termination of the study. The brain was removed from all animals exposed to either media or virus aerosols and tested for rabies using a fluorescent antibody test. Serum was obtained from all animals that survived to the end of each experiment and tested for neutralizing antibody by a fluorescent antibody virus neutralization test.

Fluorescent antibody test (FAT). Viruses were initially detected by a FAT using standard protocols (Dean \& Abelseth, 1973). Briefly, impression slides of brain tissue were fixed in acetone, washed and stained with anti-nucleoprotein fluorescein isothiocyanate-labelled monoclonal antibody (Centocor).

Antibody detection. RABV-specific antibody was detected using a fluorescent antibody virus neutralization test (Cliquet et al., 1998).

Extraction of RNA. Detection of virus within total organ samples was performed using sensitive hemi-nested RT-PCR as described previously (Johnson \& Fooks, 2005). Briefly, RNA was extracted from whole organs using TRIzol (Invitrogen). RNA was stored at $-80^{\circ} \mathrm{C}$.

RT-PCR and sequencing. RT-PCR was performed as described previously using primers JW12 and JW6(DPL) (Heaton et al., 1997). Hemi-nested PCR was carried out using primer combinations JW12 and JW10(P) or JW12 and GT1/GT6 (Johnson \& Fooks, 2005). PCR products were separated on a $1 \%$ agarose gel and visualized by ethidium bromide $\left(1 \mu \mathrm{g} \mathrm{ml}^{-1}\right)$ staining and UV illumination.

\section{RESULTS AND DISCUSSION}

\section{Virus distribution in mice challenged directly with RABV}

The survival of mice inoculated with RABV was assessed by the i.c., subdermal (footpad) and i.n. routes. The challenge virus induced rabies in all of the inoculated mice (Table 2).

Table 2. Comparison of survival following challenge with RABV through different inoculation routes

Control mice were challenged with $30 \mu \mathrm{l}$ medium and RABV mice were challenged with $30 \mu \mathrm{l} \mathrm{CVS}\left(10^{5} \mathrm{TCID}_{50} \mathrm{ml}^{-1}\right)$.

\begin{tabular}{|lcc|}
\hline $\begin{array}{l}\text { Route of } \\
\text { challenge }\end{array}$ & $\begin{array}{c}\text { Survival } \\
\text { at } 28 \text { days }\end{array}$ & $\begin{array}{c}\text { Mean days } \\
\text { to late-stage } \\
\text { disease }( \pm \text { SD })\end{array}$ \\
\hline Intranasal (media) & $5 / 5$ & - \\
Intracranial & $0 / 5$ & $4 \cdot 8( \pm 0 \cdot 45)$ \\
Subdermal (footpad) & $0 / 5$ & $6 \cdot 8( \pm 0 \cdot 45)$ \\
Intranasal & $0 / 5$ & $7( \pm 0)$ \\
\hline
\end{tabular}

The only apparent difference among the routes of challenge was the time taken to reach late-stage disease, with the two peripheral routes of inoculation (footpad and i.n.) taking a further 2 days to induce disease compared with the more direct i.c. route.

Two mice challenged by the i.n. route or control animals were sacrificed immediately after challenge to assess the distribution of CVS following introduction of virus (Fig. 1). Total RNA was extracted from the tongue, lungs and stomach (including stomach contents) to detect virus using hemi-nested PCR. All first-round amplifications were negative. However, nested PCR detected RABV in the stomach (Fig. 1, lanes 10 and 13), lung (Fig. 1, lane 11) and tongue (Fig. 1, lane 12). This suggested that virus introduced through the i.n. route became widely distributed and could find multiple routes of entry. The consistent finding of virus in the stomach (Fig. 1, lanes 10 and 13) indicated that most virus introduced by the i.n. route was swallowed and presumably rendered non-infectious.

\section{Aerosol challenge of mice with RABV}

Having established the consequences of i.n. challenge, we proceeded to assess the ability of RABV to infect mice using aerosolized virus. Tenfold dilutions of challenge virus were prepared and used to expose groups of mice to increasing concentrations of CVS. Two mice were sacrificed from the control group and the group exposed to aerosol generated from a suspension containing $10^{5} \mathrm{TCID}_{50} \mathrm{CVS} \mathrm{ml}^{-1}$. Virus distribution was assessed as described above. Hemi-nested PCR demonstrated the presence of RABV in the lungs (Fig. 2, lanes 7 and 10) and stomach (lanes 9 and 12) in both mice. This observation suggested that aerosolized virus was inhaled and ingested in a similar manner to direct i.n. challenge.

The detection of virus in lung vacuoles suggested that the aerosol particles were of the optimum size for uptake. The remaining mice were monitored for 28 days using a scoring system developed for i.c. challenge for RABV (see Methods). Mice challenged with $10^{5} \mathrm{TCID}_{50} \mathrm{ml}^{-1}$ uniformly developed signs of disease by day 7 following challenge and were

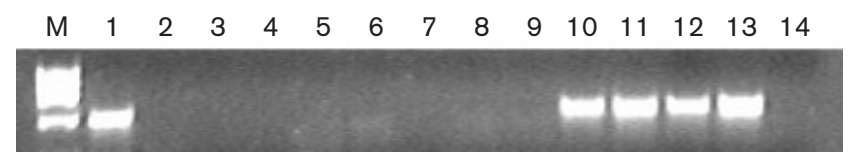

Fig. 1. RT-PCR detection of RABV in the lungs, stomach and tongue of mice challenged by intranasal inoculation. Organ samples were removed immediately after i.n. challenge with CVS (30 $\mu \mathrm{l}$, $10^{5} \mathrm{TCID}_{50}$ ). Lanes: $1,30 \mu \mathrm{l}$ inocula (CVS) (positive control); 2, no-template (negative) control; 3-8, control mice: tongue (3 and 6), stomach (4 and 7), lungs (5 and 8 ); 9-14, CVSchallenged mice: tongue (9 and 12), stomach (10 and 13), lungs (11 and 14); $\mathrm{M}, \phi \mathrm{X} 174$ Haell digest DNA marker (Invitrogen). 


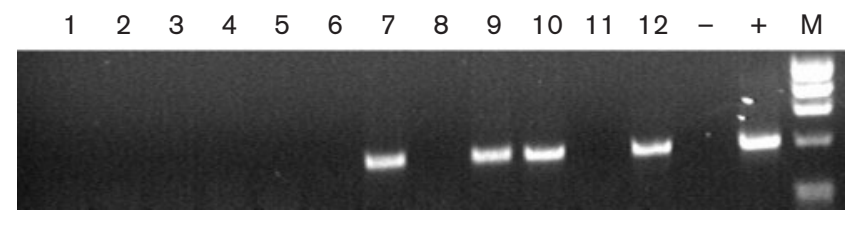

Fig. 2. RT-PCR detection of RABV in the lungs, stomach and tongue of mice challenged by aerosol exposure. Samples were obtained from duplicate animals exposed to media (lanes 1-6) or CVS (lanes 7-12) and RNA was extracted from lungs (lanes 1, 4, 7 and 10), tongue (lanes 2, 5, 8 and 11) and stomach (lanes 3, 6, 9 and 12). The positive ( + ) and negative (-) controls were the same as those described in the legend to Fig. 1. M, $\phi$ X174 Haell digest DNA marker (Invitrogen).

sacrificed on day 8 (Fig. 3). The group exposed to $10^{4}$ $\mathrm{TCID}_{50} \mathrm{ml}^{-1}$ were slower to develop signs of disease, the first showing disease signs on day 9. Four mice in this group developed signs of disease by day 12 . The remaining mice in this group were healthy until the end of the study. Within the group exposed to the highest dilution of virus $\left(10^{3}\right.$ $\mathrm{TCID}_{50} \mathrm{ml}^{-1}$ ), only one mouse developed signs of disease at day 10 (score of 1 ) and was sacrificed on day 12 when signs of disease worsened. All of the mice that developed signs of disease from each group were FAT positive and the survivors at day 28 were all FAT negative. Serum samples taken from four of the survivors from each group were assessed for rabies neutralizing antibodies by a fluorescent antibody virus neutralization test. No difference was observed in the titre derived from the medium- and low-titre challenge groups (reciprocal titres of 3.05 and $1 \cdot 73$, respectively) when compared with the media control group (reciprocal titre of $2 \cdot 05$ ) and all were considered antibody negative.

These data confirmed previous studies of experimental oral and nasal transmission of RABV in mice, which demonstrated that CVS was able to kill mice via the i.n. route (Charlton \& Casey, 1979). Similar i.n. challenge studies with

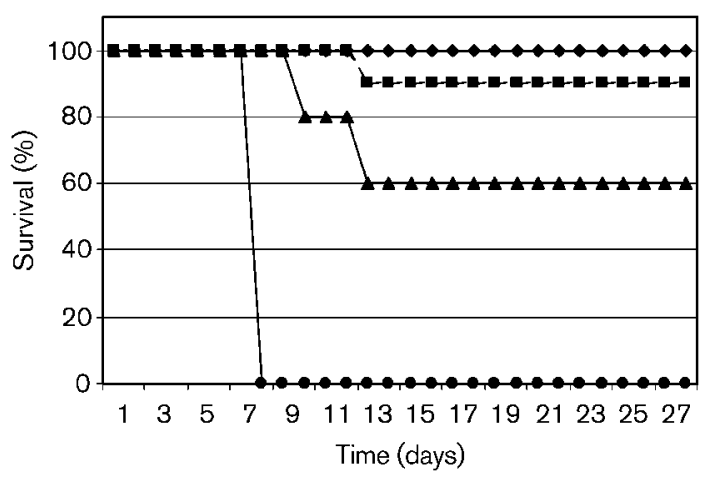

Fig. 3. Survival curves of mice challenged with a dilution series of RABV by aerosol exposure. Groups of 8-10 mice were exposed to medium $\left(\boldsymbol{)}\right.$ ) or virus suspensions containing $10^{5}$ $(\mathbf{O}), 10^{4}(\mathbf{\Delta})$ or $10^{3}(\boldsymbol{\square}) \mathrm{TCID}_{50} \mathrm{ml}^{-1} \mathrm{RABV}$.
CVS have shown that the virus can be detected shortly after exposure within the olfactory bulb, suggesting that this is the most probable route from the nasal mucosa to the brain (Jenson et al., 1969; Lafay et al., 1991). However, early infection of the trigeminal nerve has also been observed following i.n. challenge (Lafay et al., 1991) and could indicate an alternative route of spread.

\section{EBLV-2 aerosol challenge of mice}

EBLV-2 is a lyssavirus closely related to RABV and causes a rabies-like disease in bats of the Myotis species, the probable host reservoir for this virus, and in man (Fooks, 2004). Current knowledge of the virulence of this virus is limited and is based mainly on analogous data from RABV (Constantine, 1966; Baer \& Bales, 1967; Selimov et al., 1969; Baer et al., 1977).

To investigate the ability of this virus to infect mice by the i.n. and aerosol routes, we challenged two groups of mice with EBLV-2. The titre for this virus was over tenfold less than that obtained for RABV due to a failure of this virus to adapt to low-serum conditions in BHK-21 cells. However, this was equivalent to an effective aerosol dose for RABV. Intranasal challenge with $30 \mu \mathrm{l}$ inoculum $\left(10^{3 \cdot 5} \mathrm{TCID}_{50}\right)$ resulted in the development of disease in two mice on days 16 and 18. Both were FAT positive for lyssavirus. Following aerosol challenge, two mice were sacrificed and viral genomic RNA was measured within the tongue, lungs and stomach. No virus could be detected during the first round of RT-PCR (data not shown). However, EBLV-2 could be detected in the lungs of the two challenged mice using a hemi-nested pan-lyssavirus PCR (Fig. 4a) and a hemi-nested PCR designed to differentiate genotype 1 from genotype 6 (Fig. 4b). No virus could be detected associated with the tongue or stomach. Despite evidence of low-level exposure, no mice from the virus-challenged group developed signs of rabies (Fig. 5). The aerosol-challenged group was maintained for 90 days without development of disease (data not shown). In the surviving mice, there was no evidence of seroconversion, suggesting that the mice had been incompletely challenged. Although there was no evidence that aerosolization was effective in the EBLV-2 challenge model, we cannot exclude that this observation was as a result of the low dose used to challenge the mice.

In conclusion, we found that mice (strain RIII) were highly susceptible to RABV (CVS) via all routes of challenge. There was an extended incubation period via the i.n. route compared with direct stereotactic injection of virus into the brain of susceptible mice. We were unable to calculate the precise dose of virus delivered, as the airborne stability of RABV is unknown. However, in this apparatus, an aerosol generated from a suspension containing $10^{3}$ p.f.u. $\mathrm{ml}^{-1}$ of a stable virus such as Venezuelan equine encephalitis virus (VEEV) would be expected to deliver a mouse-received dose of $<10$ p.f.u. (R. Phillpotts, unpublished data). These data suggest that RABV is highly infectious for mice by the aerosol route. Similar results have been found in a range of 


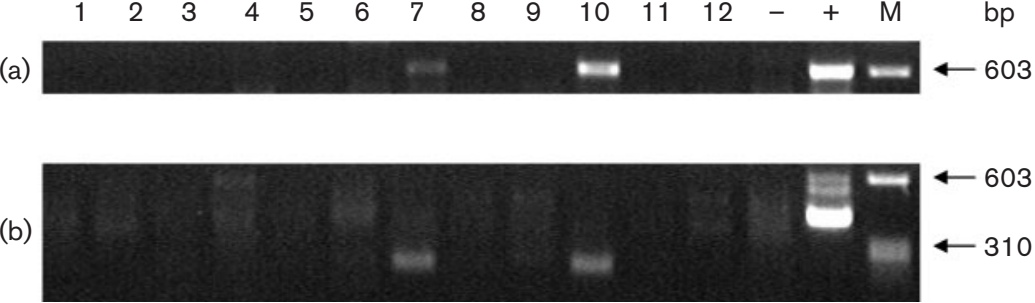

Fig. 4. RT-PCR detection of EBLV-2 in the lungs of mice challenged by aerosol exposure. Detection of EBLV-2 using hemi-nested pan-lyssavirus primers JW12 and JW1O(P) (a) or genotype 1/genotype 6 differentiating primers JW12 and GT1/GT6 (b) in the lungs (lanes 1, 4, 7 and 10), tongue (lanes 2, 5, 8 and 11) or stomach (lanes 3, 6, 9 and 12) in control (lanes 1-6) or EBLV-2-exposed (lanes 7-12) mice. rodent models (Hronovsky \& Benda, 1969a, b). RABV was detectable in the lungs and stomach of the airbornechallenged mice, suggesting that the virus was both inhaled and ingested during exposure. This has implications for the site at which the virus enters the host and suggests that RABV entry is likely to occur at the nasal mucosa or possibly at sites within the lung. The greater innervation found within the nasal mucosa favours this site. In a separate aerosol-challenge experiment, aerosols generated from a suspension of EBLV-2 at a concentration $10^{3 \cdot 5} \mathrm{TCID}_{50} \mathrm{ml}^{-1}$ failed to infect mice, suggesting that EBLV-2 has a lower virulence in direct comparison with 'fixed' RABV strains. In previous studies using VEEV, $10^{3 \cdot 0} \mathrm{TCID}_{50} \mathrm{ml}^{-1}$ in the spray fluid delivered approximately $3 \mathrm{TCID}_{50}$ to each mouse (Elvin et al., 2002). In this study, the fixed RABV strain used was relatively pathogenic by the airborne route, as this dose killed $10 \%$ of the airborne-challenged mice. In contrast, none of the mice died from the airborne EBLV-2 challenge at $10^{3 \cdot 5} \mathrm{TCID}_{50} \mathrm{ml}^{-1}$, with each mouse receiving an estimated 6 TCID $_{50}$. Our data suggest that EBLV-2 is less pathogenic by the airborne route than RABV or is less stable following aerosolization.

In this experiment, there was no evidence of seroconversion in the surviving mice, indicating that EBLV-2 failed to cause even a limited infection. There was evidence of viral RNA

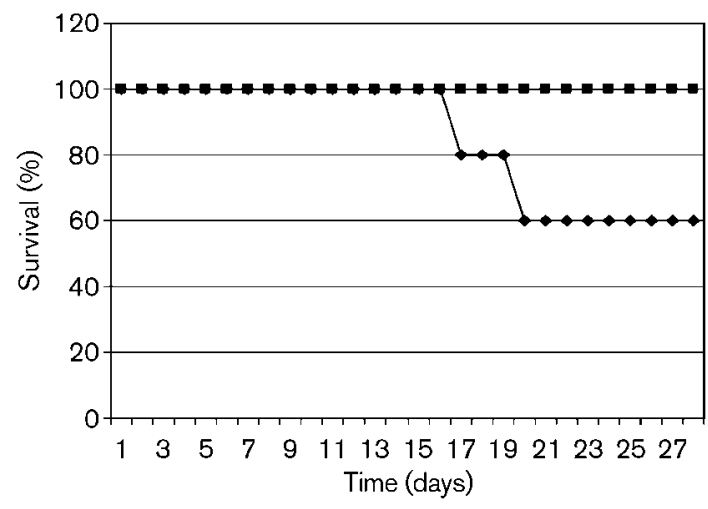

Fig. 5. Survival curves of mice challenged with EBLV-2 by the i.n. $\left(\boldsymbol{\nabla}, 10^{3.5} \mathrm{TCID}_{50} \mathrm{ml}^{-1}\right)$ or aerosol $(\boldsymbol{\square}$, aerosol generated from suspension containing $10^{3.5} \mathrm{TCID}_{50} \mathrm{ml}^{-1}$ ) challenge route. The negative-control group has been omitted from the figure for clarity. within the exposed lung (Fig. 4a, b); however, we must conclude that this was not sufficient to cause infection or induce an immune response.

This study confirms the ability of two lyssaviruses to infect a mammalian model through i.n. exposure. RABV was highly effective at infecting mice by aerosol exposure, emphasizing the need to minimize risk of generating lyssavirus aerosols within the laboratory environment. Moreover, it is essential that all laboratory staff receive pre-immunization against RABV to reduce substantially the risk following exposure to the virus. This study also suggests a risk, albeit low, to individuals in confined spaces that have contact with infected bats, which may be excreting virus in airborne droplets. Our results do not exclude the possibility of transmission of RABV by routes other than a direct bite.

\section{ACKNOWLEDGEMENTS}

This study was supported financially by an internal VLA grant (Seedcorn SC0141) and by the Department for Environment, Food and Rural Affairs (Defra), UK.

\section{REFERENCES}

Arai, Y. T., Kuzmin, I. V., Kameoka, Y. \& Botvinkin, A. D. (2003). New lyssavirus genotype from the lesser mouse-eared bat (Myotis blythi), Kyrghyzstan. Emerg Infect Dis 9, 333-337.

Atanasiu, P. (1965). Transmission of rabies by respiratory route to laboratory animals. C R Acad Sci Hebd Seances Acad Sci D 261, 277-279 (in French).

Badrane, H., Bahloul, C., Perrin, P. \& Tordo, N. (2001). Evidence of two Lyssavirus phylogroups with distinct pathogenicity and immunogenicity. J Virol 75, 3268-3276.

Baer, G. H. \& Bales, G. L. (1967). Experimental rabies infection in the Mexican freetail bat. J Infect Dis 117, 82-90.

Baer, G. M., Cleary, W. F., Diaz, A. M. \& Perl, D. F. (1977). Characteristics of 11 rabies virus isolates in mice: titers and relative invasiveness of virus, incubation period of infection, and survival of mice with sequelae. J Infect Dis 136, 336-345.

Botvinkin, A. D., Kuzmin, I. V. \& Rybin, S. N. (1996). The unusual bat lyssavirus Aravan from Central Asia. Myotis 34, 101-104.

Botvinkin, A. D., Poleschuk, E. M., Kuzmin, I. V., Borisova, T. I., Gazaryan, S. V., Yager, P. \& Rupprecht, C. E. (2003). Novel lyssaviruses isolated from bats in Russia. Emerg Infect Dis 9, $1623-1625$. 
Bourhy, H., Kissi, B., Lafon, M., Sacramento, D. \& Tordo, N. (1992). Antigenic and molecular characterization of bat rabies virus in Europe. J Clin Microbiol 30, 2419-2426.

Bourhy, H., Kissi, B. \& Tordo, N. (1993). Molecular diversity of the Lyssavirus genus. Virology 194, 70-81.

Charlton, K. M. \& Casey, G. A. (1979). Experimental oral and nasal transmission of rabies virus in mice. Can J Comp Med 43, 10-15.

Cliquet, F., Aubert, M. \& Sagné, L. (1998). Development of a fluorescent antibody virus neutralisation test (FAVN test) for the quantitation of rabies-neutralising antibody. J Immunol Methods 212, 79-87.

Constantine, D. G. (1962). Rabies transmission by nonbite route. Public Health Rep 77, 287-289.

Constantine, D. G. (1966). Transmission experiments with bat rabies isolates: responses of certain Carnivora to rabies virus isolated from animals infected by nonbite route. Am J Vet Res 27, 13-15.

Constantine, D. G. (1967). Rabies transmission by air in bat caves. In Public Health Service Publication No. 1617, pp. 1-51. Atlanta, GA: National Communicable Disease Center.

Constantine, D. G., Emmons, R. W. \& Woodie, J. D. (1972). Rabies virus in nasal mucosa of naturally infected bats. Science 175, $1255-1256$.

Dean, D. J. \& Abelseth, M. K. (1973). The fluorescent antibody test. In Laboratory Techniques in Rabies, 3rd edn, pp. 73-84. Edited by M. M. Kaplan \& H. Koprowski. Geneva: World Health Organization.

Elvin, S. J., Bennett, A. M. \& Phillpotts, R. J. (2002). Role for mucosal immune responses and cell-mediated immune functions in protection from airborne challenge with Venezuelan equine encephalitis virus. I Med Virol 67, 384-393.

Fooks, A. R. (2004). The challenge of new and emerging lyssaviruses. Expert Rev Vaccines 3, 333-336.

Fooks, A. R., Brookes, S. M., Johnson, N., McElhinney, L. M. \& Hutson, A. M. (2003a). European bat lyssaviruses: an emerging zoonosis. Epidemiol Infect 131, 1029-1039.

Fooks, A. R., McElhinney, L. M., Pounder, D. J. \& 8 other authors (2003b). Case report: isolation of a European bat lyssavirus type 2a from a fatal human case of rabies encephalitis. J Med Virol 71, 281-289.

Heaton, P. R., Johnstone, P., McElhinney, L. M., Cowley, R., O'Sullivan, E. \& Whitby, J. E. (1997). Heminested PCR assay for detection of six genotypes of rabies and rabies-related viruses. J Clin Microbiol 35, 2762-2766.

Hronovsky, V. \& Benda, R. (1969a). Experimental inhalation infection of laboratory rodents with rabies virus. Acta Virol 13, 193-197.

Hronovsky, V. \& Benda, R. (1969b). Development of inhalation rabies infection in suckling guinea pigs. Acta Virol 13, 198-202.

Irons, J. V., Eads, R. B., Grimes, J. E. \& Conklin, A. (1957). The public health importance of bats. Tex Rep Biol Med 15, 292-298.
Jenson, A. B., Rabin, E. R., Bentinck, D. C. \& Melnick, J. L. (1969). Rabiesvirus neuronotis. J Virol 3, 265-269.

Johnson, N. \& Fooks, A. R. (2005). Archival study of a Finnish isolate from the 1988/89 rabies outbreak. Arch Virol 150, 1407-1414.

Johnson, N., Selden, D., Parsons, G., Healy, D., Brookes, S. M., McElhinney, L. M., Hutson, A. M. \& Fooks, A. R. (2003). Isolation of a European bat lyssavirus type 2 from a Daubenton's bat in the United Kingdom. Vet Rec 152, 383-387.

Kent, J. R. \& Finegold, M. F. (1960). Human rabies transmitted by the bite of a bat: with comments on the duck-embryo vaccine. $N$ Engl J Med 263, 1058-1065.

King, A. A. (1996). Cell culture of rabies virus. In Laboratory Techniques in Rabies, 4th edn, pp. 114-130. Edited by F.-X. Meslin, M. M. Kaplan \& H. Koprowski. Geneva: World Health Organization. Lafay, F., Coulon, P., Astic, L., Saucier, D., Riche, D., Holley, A. \& Flamand, A. (1991). Spread of the CVS strain of rabies virus and of the avirulent mutant $\mathrm{AvO} 1$ along the olfactory pathways of the mouse after intranasal inoculation. Virology 183, 320-330.

Messenger, S. L., Smith, J. S. \& Rupprecht, C. E. (2002). Emerging epidemiology of bat-associated cryptic cases of rabies in humans in the United States. Clin Infect Dis 35, 738-747.

Messenger, S. L., Smith, J. S., Orciari, L. A., Yager, P. A. \& Rupprecht, C. E. (2003). Emerging pattern of rabies deaths and increased viral infectivity. Emerg Infect Dis 9, 151-154.

Phillpotts, R. J., Brooks, T. J. G. \& Cox, C. S. (1997). A simple device for the exposure of animals to infectious microorganisms by the airborne route. Epidemiol Infect 118, 71-75.

Selimov, M. A., Marinina, V. P., Nikitina, L. F. \& llyasova, R. S. (1969). Experimental respiratory infection induced by rabies virus variants adapted to tissue culture. Acta Virol 13, 135-138.

Tillotson, J. R., Axelrod, D. \& Lyman, D. O. (1977). Rabies in a laboratory worker - New York. Morb Mortal Wkly Rep 26, 183-184.

Tordo, N. (1996). Characteristics and molecular biology of the rabies virus. In Laboratory Techniques in Rabies, 4th edn, pp. 28-51. Edited by F.-X. Meslin, M. M. Kaplan \& H. Koprowski. Geneva: World Health Organization.

Warrell, M. J. \& Warrell, D. A. (2004). Rabies and other lyssavirus diseases. Lancet 363, 959-969.

Winkler, W. G. (1968). Airborne rabies virus isolation. Wildl Dis 4, $37-40$.

Winkler, W. G. (1975). Airborne rabies. In The Natural History of Rabies, vol. II, pp. 115-121. Edited by G. M. Baer. New York: Academic Press.

Winkler, W. G., Baker, E. F., Jr \& Hopkins, C. C. (1972). An outbreak of non-bite transmitted rabies in a laboratory animal colony. Am J Epidemiol 95, 267-277.

Winkler, W. G., Fashinell, T. R., Leffingwell, L., Howard, P. \& Conomy, P. (1973). Airborne rabies transmission in a laboratory worker. JAMA (J Am Med Assoc) 226, 1219-1221. 